\title{
Operasyonel Ofis Mobilyası Tasarımının RULA Yöntemi ile Ergonomik Analizi ve Yeniden Tasarımı
}

\author{
Neslihan TOP ${ }^{*}$,a \\ a, ${ }^{*}$ Gazi Üniversitesi Endüstriyel Tasarım Mühendisliği Bölümü, ANKARA 06500, TÜRKIYE
}

\begin{tabular}{l} 
MAKALE \\
BILGISI \\
\hline Alınma: 18.10 .2019 \\
Kabul: 29.12.2019 \\
\hline \\
Anahtar Kelimeler: \\
Ofis mobilyası, \\
Ergonomik analiz, \\
RULA, \\
Dijital insan \\
modelleme \\
*Sorumlu Yazar: \\
e-posta: \\
neslihantop@gazi.edu. \\
tr
\end{tabular}

Ofis mobilyası tasarımında, çalışanların duruş pozisyonları sebebiyle kas ve iskelet sistemi üzerinde meydana gelebilecek riskler göz önünde bulundurulmalıdır. Uzun süre masa başında çalışan ve aynı duruş pozisyonda oturmak durumunda kalan bireylerde mesleki rahatsızlıklar ortaya çıkabilmektedir. Bu rahatsızlıkların önceden tespiti ve düzenlenmesi için ergonomik analiz yöntemlerinden yaralanılmaktadır. Ofiste çalışan bireylerin vücut ve boy ölçülerine uygun olarak yeniden tasarım işlemi gerçekleştirilmektedir. Bu çalışma kapsamında tasarlanan operasyonel ofis mobilyası grubu ile çalışanların ihitiyaçları tek bir alanda giderilmeye çalışılmıştır. Tasarımda var olan dinlenme ve toplanma alanları ile çalışanlar gün içerisinde mekan değişikliği yaparak farklı alanlarda çalışma imkanına sahip olabileceklerdir. Ayrıca çalışma alanı, bireylerin maksimum iletişim halinde kalabileceği şekilde düzenlenerek çalışma süresince sosyalleşme olanağı arttırılmıştır. Bu çalışmada, çalışanların ihtiyaçlarına cevap vermesi amacıyla minimum alanda maksimum fonksiyon prensibi ile geliștirilen modüler ofis mobilyası sisteminin ergonomik değerlendirilmesi gerçekleştirilmiştir. Rhinoceros programında üç boyutlu (3B) modelleme işlemi tamamlanan operasyonel ofis mobilyası tasarımı, CATIA programının RULA (Rapid Upper Limb Assessment) aracı kullanılarak ortalama antropometrik verilere sahip bir insana göre ergonomik açıdan analiz edilmiştir. Elde edilen sonuçlara göre tasarım üzerinde gerekli değişiklikler sağlanmıştır.

\section{Ergonomic Analysis and Redesign of Operational Office Furniture Design by RULA Method}

\begin{tabular}{l} 
ARTICLE \\
INFO \\
\hline Received: 18.10 .2019 \\
Accepted: 29.12 .2019 \\
\hline Keywords: \\
Office furniture, \\
Ergonomic analysis, \\
RULA, \\
Digital Human \\
Modelling \\
*Corresponding \\
Authors \\
e-mail: \\
neslihantop@gazi.edu. \\
tr
\end{tabular}

\begin{abstract}
In office furniture design, the risks that may occur on the musculoskeletal system due to the posture positions of the employees should be taken into consideration. Occupational diseases may occur in individuals who work at a desk for a long time and have to sit in the same posture position. Ergonomic analysis methods are used to detect and regulate these disorders. Re-design process is carried out in accordance with body and height measurements of individuals working in the office. With the operational office furniture group designed within the scope of this study, the needs of the employees were tried to be met in a single area. With the resting and gathering areas in the design, employees will have the opportunity to work in different areas by changing the space during the day. In addition, the study area was arranged in such a way that individuals could stay in maximum communication and the opportunity to socialize during the study was increased. In this study, ergonomic evaluation of modular office furniture system which was developed with the principle of maximum function in minimum area was realized in order to meet the needs of employees. In the Rhinoceros program, three-dimensional (3D) modeling of operational office furniture design has been completed and analyzed by using CATIA RULA (Rapid Upper Limb Assessment) tool in terms of anthropometric data for an average human. According to the results, necessary changes were made on the design.
\end{abstract}




\section{GİRIŞ (INTRODUCTION)}

Ergonomik bir işyeri ya da ürün geliştirme sürecinde, o alanı veya ürünü kullanacak olan bireylerin kapasite ve özelliklerine uygun bir tasarım oluşturulmalıdır. Geliştirilen ürün, işlevsel, kullanıcı odaklı, ekonomik ve estetik kaygıları taşıdığ takdirde ergonomik olarak nitelendirilebilmektedir. Kullanıcı ihtiyaçlarına uygun olarak geliştirilen bir tasarım, kullanıciların antropometrik verilerine uygun ve işlevini yerine getirebilir olmalıdır [1].

Antropometri, bireylerin vücut boy ve özelliklerinin sayısal olarak ifade edilmesidir. Antropometri ile birlikte bireylerin yaşadıkları bölge ve milliyetlerine göre morfolojik özellikleri incelenerek elde edilen veriler doğrultusunda tasarımlar geliştirilmektedir. İnsanlar yaşadıkları çevre ve kalıtsal özellikleri doğrultusunda şekillenmektedir. Aynı kalıtsal özelliklere sahip olup farklı bölgede yaşayan insanların bile farklı antropometrik verilere sahip olduğu görülmektedir. $\mathrm{Bu}$ sebeple, ürün geliştirme sürecinde o bölgede yaşayan insanların kendine has antropometrik verileri dikkate alınmalıdır [2-5].

Tek bir kullanıcı için işyeri veya ürün tasarımının mümkün olduğu durumlarda kişiye özel tasarımlar geliştirilerek yüksek maliyetler elde edilmektedir. Ünlü tasarımcıların markalaşmış tasarımları ya da astronotlar için hazırlanan iş istasyonları bu duruma örnek olarak gösterilebilmektedir. Birçok engelli bireyin fiziksel özelliklerindeki önemli değişim sebebiyle de özel tasarımlara gerek duyulmaktadır. Bu durumlar dışındaki bütün tasarım süreçlerinde, o bölgede bulunan popülasyona uygun ürünler oluşturulmalıdır [6].

İşyeri tasarımında verimin arttırılması için kullanılan tüm ekipmanların o iș yerinde çalışmakta olan bireylerin antropometrik verilerine uygun olarak geliştirilmesi gerekmektedir [7]. Böylece, çalışanlarda meydana gelebilecek mesleki rahatsızlıkların da önüne geçilmesi mümkün olmaktadır. Ergonomik işyeri tasarımının en önemli olduğu alanlardan biri de ofis tasarımlarıdır. Ofis çalışanları çoğunlukla uzun saat boyunca masa başında ve ekran karşısında günü tamamlamaktadır. Ofiste kullanılan tüm mobilyaların ofiste çalışan bireylerin vücut ölçülerine uygun olarak ergonomik olması gerekmektedir. Ofisteki gürültü, yetersiz 1s1 ve ışık seviyesi ile kullanılan ürünlerin ergonomisi o işyerindeki verimi doğrudan etkilemektedir. Ergonomik olmayan mobilyaların kullanımı, çalışanların kas ve iskelet sisteminde baskı meydana getirerek kalıcı rahatsızlıklara sebebiyet verebilmektedir. Ofis tasarımları, çalışanların gün boyu aynı duruş pozisyonunda kalmasını engelleyecek farklı çalışma alanlarına da sahip olmalıdır. Gün içerisinde çalışanların daha aktif etkileşim halinde olacağ 1 alanlar oluşturularak iş verimi arttırılmalıdır. Ofisler, çalışanların fiziksel ve psikolojik ihtiyaçlarına cevap vermelidir. Oluşturulan alanlar hem kişiselleşme hem de sosyalleşme imkanını tanımalıdır [8-10].

$\mathrm{Bu}$ çalışma kapsamında, The XXIXth International Conference Research for Furniture Industry sempozyumunda sunulan "A Study On Modular Operational Workıng System Design In The Office Furniture Sector" başlıklı bildiride [9] tasarımı gerçekleştirilen modüler yapıdaki ofis tasarımının ergonomik analizi gerçekleştirilmiştir. Çalışanların gün boyu dinamizmini ve hareket imkânını yüksek tutmaya firsat veren bu tasarım, farklı birimlerden meydana gelmektedir (Şekil 1). $\mathrm{Bu}$ birimler işyerinin hacmine uygun doğrultuda arttırılarak farklı șekillerde kullanılabilmektedir. Şekil 2'de bu birimlerin farklı kullanımına örnekler verilmiştir. Çalışma, dinlenme ve toplantı alanlarından oluşan birimlerin ortalama ölçüde antropometrik verilere sahip bir bireye göre ergonomisi CATIA programının RULA aracı kullanılarak analiz edilmiștir. Elde edilen analiz sonuçlarına göre tasarımın zayıf tarafları tespit edilerek gerekli düzenlemeler gerçekleştirilmiştir.

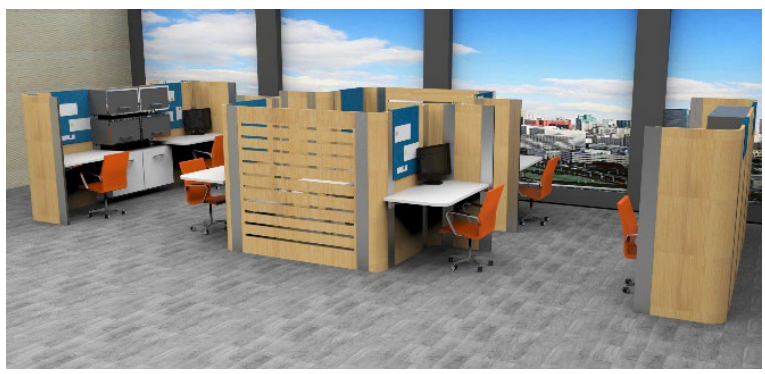

Şekil 1. Modüler yapıdaki ofis tasarımı (Modular office design) 

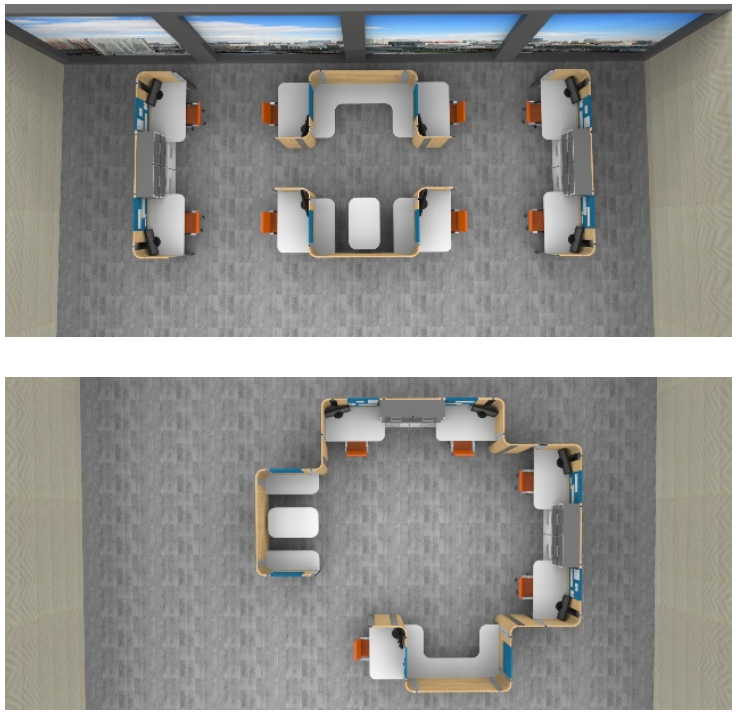

Şekil 2. Birimlerin farklı dizilimiyle oluşan ofis yap1lar1 (Office structures formed by different arrangement of units)

\section{RULA ANALIZİ (RULA ANALYSIS)}

Teknolojinin gelişimi ile ergonomik analiz yöntemleri, bilgisayar destekli tasarım (CAD) programlarında uygulanmaya başlanmıştır [11]. CAD programlarında oluşturulan dijital insan modelleri ile ergonomik açıdan analiz edilecek olan duruş ya da aktivite bilgisayar ortamına simüle edilebilmektedir. Böylece gereksiz prototipler ortadan kaldırılarak tespit edilen problemler üretim öncesi süreçlerde tespit edilebilmektedir [12, 13].

Ergonomik analiz uygulamalarında farklı yöntemler kullanılmaktadır. $\mathrm{Bu}$ yöntemler, insan kas-iskelet sisteminin hangi bölgesinde baskı oluştuğunu farklı teknikler ile değerlendirmektedir. $\mathrm{Bu}$ amaçla kullanılan ergonomik analiz yöntemleri arasında; RULA (Rapid Upper Limb Assessment), NIOSH (National Institute for Occupational Safety and Health), REBA (Rapid Entire Body Assesment), OWAS (Ovako Working Posture Analysing System) ve LMM (Lumbar Motion Monitor) bulunmaktadır [14-17]. RULA yöntemi ile vücudun üst bölgelerinde oluşan baskı tespit edilerek gerekli düzenlemeler yapılırken, REBA yöntemi ile vücudun boyun, gövde, bacak ve alt, üst kol ile bilek bölümleri ayrı ayrı gruplandırılarak bu bölgelerdeki esneme, uzama, eğilme, rotasyon açıları ile ergonomik analiz işlemi tamamlanmaktadır. NIOSH yöntemi, kaldırma işleri sırasındaki riskleri tespiti için bir kaldırma denklemini içermektedir [18]. OWAS ergonomic analiz metodu ise çalışma sırasında yanlış duruş sebebiyle kas ve iskelet sisteminde meydana gelebilecek rahatsızlıkların gözleme dayalı olarak tespit edilmesidir [19].

Bu çalışmada ergonomik analiz işlemi için CATIA V5 R21 programının RULA aracı kullanılmıştır. RULA analizi ile üst esktremite aktivitelerinde (boyun, gövde, kol, bilek gibi) risk yaratacak duruş pozisyonları tespit edilerek gerekli iyileştirmeler yapılmaktadır [20]. CATIA programı ile Dijital İnsan Modelleme (DHM) yaklaşımı kullanılarak bir puanlama sistemi sonucu analiz işlemi tamamlanmaktadır [21]. Analiz sonucu elde edilen puanlar 1 ila 7 arasında değişmekte ve renkler ile temsil edilmektedir. CATIA programı ile uygulanan RULA araci sonucu elde edilen tablodaki puan ve renk değerleri Tablo 1'de verilmiştir.

Tablo 1. RULA analizi puan tablosu değerlendirmesi (RULA analysis score table assessment) $[7,22]$

\begin{tabular}{|l|c|c|c|c|c|c|c|}
\hline $\begin{array}{l}\text { Vücudun } \\
\text { bölümü }\end{array}$ & Puan & 1 & 2 & 3 & 4 & 5 & 6 \\
\hline Üst kol & $1-6$ & & & & & & \\
\hline Önkol & $1-3$ & & & & & & \\
\hline Bilek & $1-4$ & & & & & & \\
\hline Bilek bükümü & $1-2$ & & & & & & \\
\hline Boyun & $1-6$ & & & & & & \\
\hline Gövde & $1-6$ & & & & & & \\
\hline
\end{tabular}

Analiz sonucu elde edilen tablodaki puan ve renklerin anlamı ise Tablo 2'de verilmiştir.

Tablo 2. RULA tablosunun yorumlanmas1 (Interpretation of RULA table) [23]

\begin{tabular}{|l|l|l|}
\hline $\begin{array}{l}\text { RULA } \\
\text { puan1 }\end{array}$ & Risk seviyesi & Faaliyet \\
\hline $1-2$ & $\begin{array}{l}\text { İhmal } \\
\text { edilebilir }\end{array}$ & Kabul edilebilir \\
\hline $3-4$ & Düşük & $\begin{array}{l}\text { Daha fazla araştırma ve } \\
\text { değişiklik gerekebilir }\end{array}$ \\
\hline $5-6$ & Orta & $\begin{array}{l}\text { Araştırma ve yakında } \\
\text { gerekli değişiklikler }\end{array}$ \\
\hline 7 & Yüksek & $\begin{array}{l}\text { Soruşturma ve hemen } \\
\text { gerekli değişiklikler }\end{array}$ \\
\hline & Toplam & \\
\hline & \multicolumn{2}{|l}{} \\
\hline
\end{tabular}




\section{OPERASYONEL OFIS MOBILYASI TASARIMININ ERGONOMIK ANALIZI (ERGONOMIC ANALYSIS OF OPERATIONAL OFFICE FURNITURE DESIGN)}

Yeni ofis düzenlerinde, verimlilik ön plana çıkarılarak çalışanların birbirleriyle daha çok etkileşim halinde bulunabileceği açı tip ofisler tercih edilmektedir. Kapalı tip ofislerde birkaç kişi bulunurken, açık tip pfislerde yüzlerce kişi bir mekanda toplanmaktadır. Bu yeni düzen ile ölçüleri ayarlanabilir mobilyalar kullanılarak herkesi mutlu edecek alanlar oluşturulmak istenmektedir. Gürültü kirliliği oluşmasını engelleyecek ve çalışanlar ihtiyaç duyduğunda bireyselleşmesine izin verecek alanlar planlanmalıdır [8]. Bu amaçla tasarlanmış olan operasyonel ofis tasarımının ergonomik değerlendirmesi bu çalışma kapsamında gerçekleştirilmiştir.

Tasarlanan operasyonel ofis mobilyası çalışma, toplantı ve dinlenme bölümü ölçüleri sırası ile Şekil 3-5'de verilmiştir.

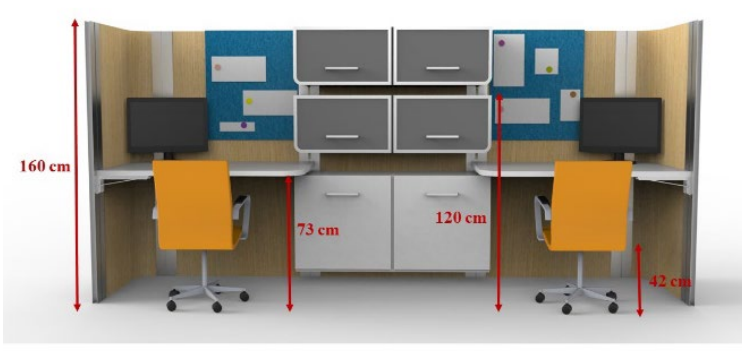

Şekil 3. Çalışma bölümü ölçüleri (Working section dimensions)

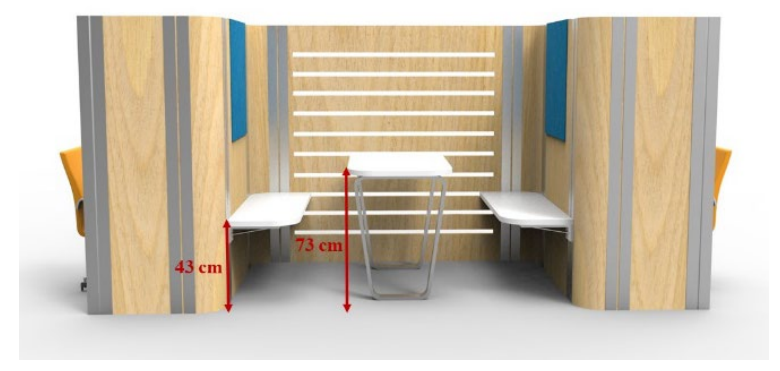

Şekil 4. Toplantı bölümü ölçüleri (Meeting section dimensions)

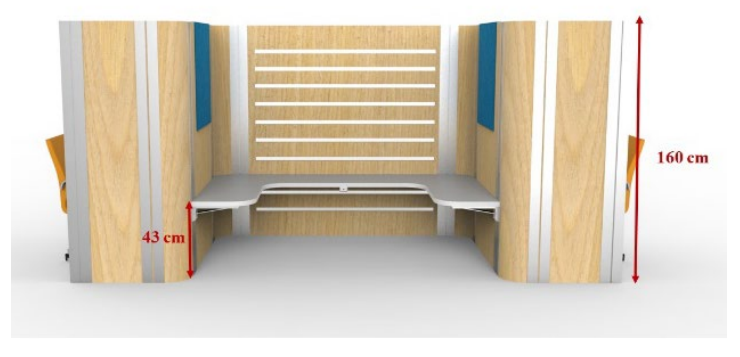

Şekil 5. Dinlenme bölümü ölçüleri (Resting section dimensions)

Ergonomik analiz işlemine ilk olarak ortalama vücut ölçülerine sahip bir dijital insan modelinin oluşturulması ile başlanmıştır. 1981 ve 2005 yıllarında yapılan Türkiye Antropometrik Araştırması sonuçlarına göre Türk erkeğinin ortalama vücut ölçü değerleri Tablo 3 'te verilmiştir.

Tablo 3. 1981 ve 2005 y1lı Türk erkeği ortalama antropometrik verileri (The average anthropometric data of Turkish men in 1981 and 2005) [1]

\begin{tabular}{|l|c|c|}
\hline \multirow{2}{*}{ Ölçü tipleri } & \multicolumn{2}{|c|}{ Ortalama erkek } \\
\cline { 2 - 3 } & 1981 & 2005 \\
\hline Boy & 168,08 & 168,8 \\
\hline Ağırlık & 66,47 & 74,74 \\
\hline Büst yüksekliği & 887,50 & 887,55 \\
\hline Alt taraf yükseklĭ̆i & - & 964,20 \\
\hline Diz yüksekliği & 503,00 & 522,99 \\
\hline & & \\
\hline Alt bacak yüksekliği & - & 483,85 \\
\hline $\begin{array}{l}\text { Omuz yüksekliği (ayakta, } \\
\text { yerden) }\end{array}$ & 1382,70 & - \\
\hline Apış arası yüksekliği & 751,30 & - \\
\hline Dirsek yüksekliği (ayakta) & 1022,60 & - \\
\hline $\begin{array}{l}\text { Tüm kol uzunluğu (ayakta, } \\
\text { omuz hareketsiz) }\end{array}$ & 827,90 & 748,54 \\
\hline Üst kol uzunluğu & - & 353,11 \\
\hline Önkol uzunluğu & - & 269,22 \\
\hline
\end{tabular}

Tablo 3'te verilen değerlere göre CATIA programında oluşturulan dijital insan modeli Şekil 6 'da verilmiştir. 


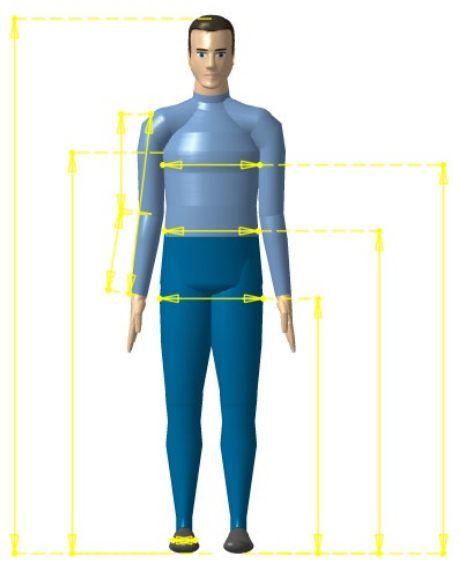

Şekil 6. CATIA programında oluşturulan dijital insan modeli (Digital human model created in CATIA program)

Dijital insan modelinin oluşturulmasının ardından ofis sisteminin çalışma bölümünün $3 \mathrm{~B}$ modeli açılarak model uygun duruş pozisyonuna getirilmiştir. Modelin üst bölmedeki depolama birimini açma durumundaki analiz sonucu Şekil 7'de verilmiştir. Elde edilen sonuçlara göre RULA analizi final puan1 4 olarak tespit edilmiştir. Bu durum, risk düzeyinin düşük olduğunu ve daha sonraki aşamalarda tasarım üzerinde değişikliklerin gerekebileceğini göstermektedir.

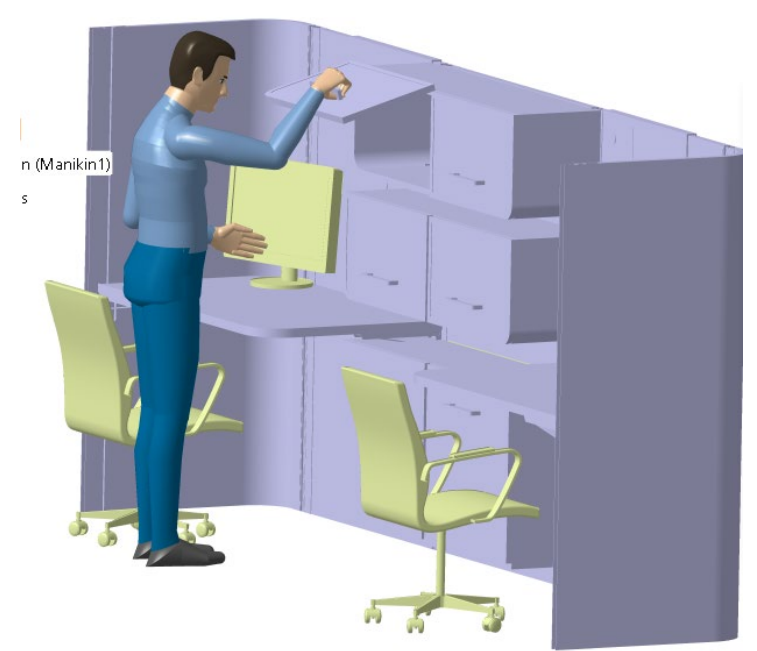

(a)

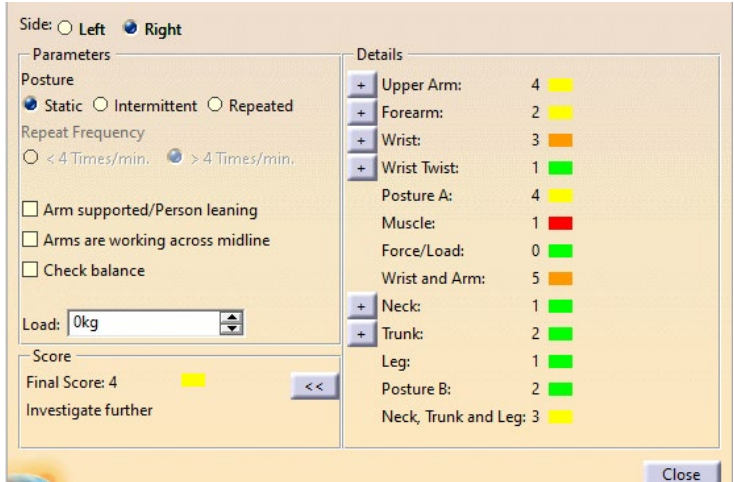

(b)

Şekil 7. (a) Üst kapağın açılması, (b) RULA analiz sonucu (a) opening the top cover, (b) RULA analysis result)

Modelin alt bölmede bulunan depolama birimi kapağını açma durumundaki RULA analiz sonucu ise Şekil 8'de verilmiştir. Analiz sonucuna göre final puanı 7 ve kırmızı renk ile gösterilmiştir. Çalışanların gün boyu bu depolama birimini kullanma sıklığı düşünelerek elde edilen final puanına göre ofis tasarımının bu bölümünde acilen değişiklik yapılması gerektiği belirlenmiştir.

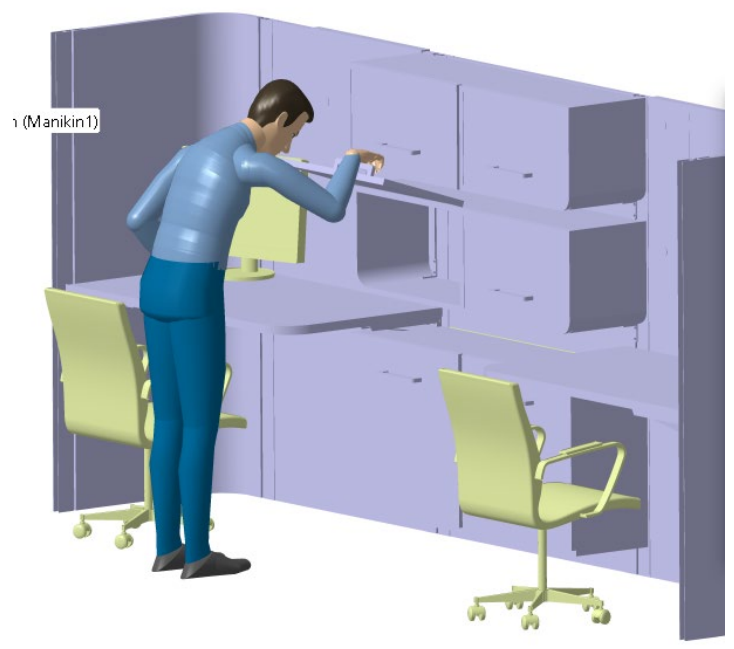

(a) 


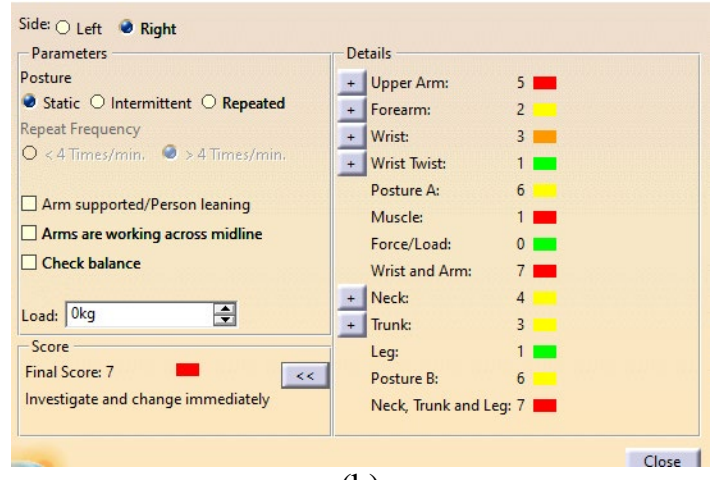

(b)

Şekil 8. (a) Alt kapağın açılması, (b) RULA analiz sonucu (a) opening the bottom cover, (b) RULA analysis result

Bir sonraki aşamada, modelin masada çalışma durumundaki pozisyonunun analiz sonucu Şekil 9'da verilmiştir. Tablodan elde edilen sonuçlara göre final puanı 3 ve sarı renk ile belirtilmiştir. Dolayısıyla tasarımın bu bölümünde ergonomik açıdan bir risk bulunmamaktadır.

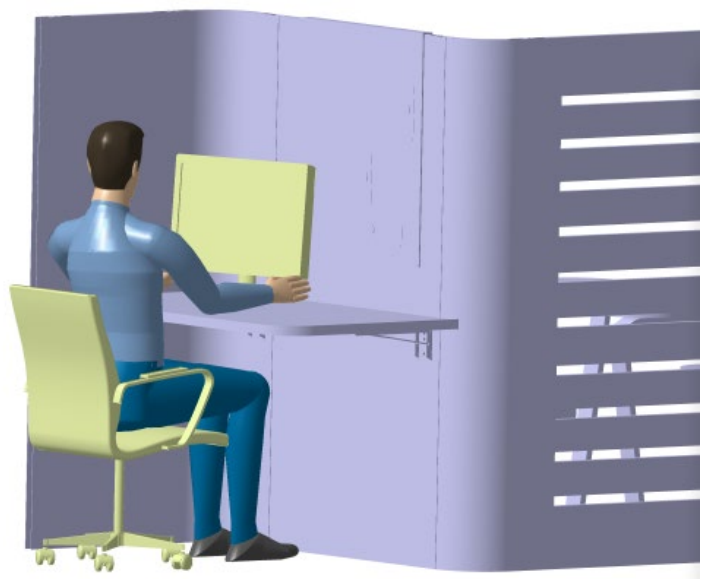

(a)

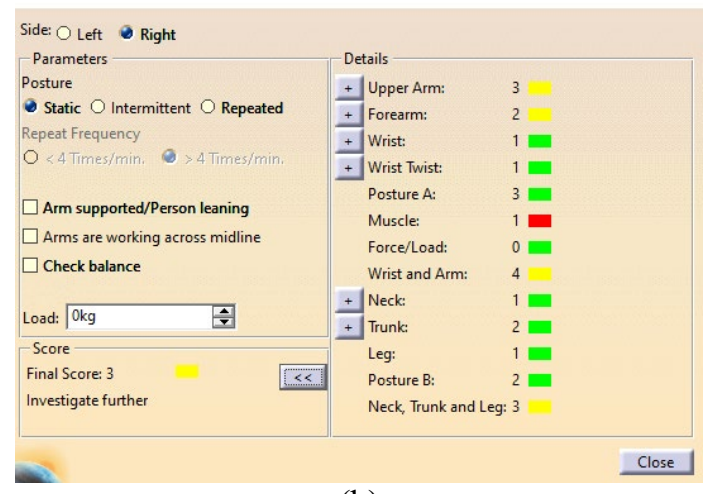

(b)

Şekil 9. (a) Masada çalışılması, (b) RULA analiz sonucu (a) Working at the table, (b) RULA analysis result
Modelin alt kısımda bulunan çöp bölümüne oturur durumdayken ulaşmak istemesi durumunda RULA analiz sonucu Şekil 10'da verilmiştir. Final puanı 4 ve sarı renk ile belirtilmiştir. Bu durum, duruş pozisyonunun risk oluşturmadığını ancak ileride değişiklik gerekebileceğini belirtmektedir.

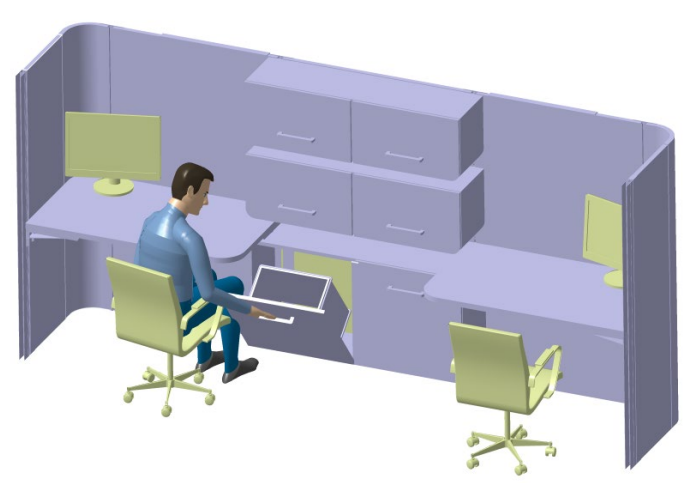

(a)

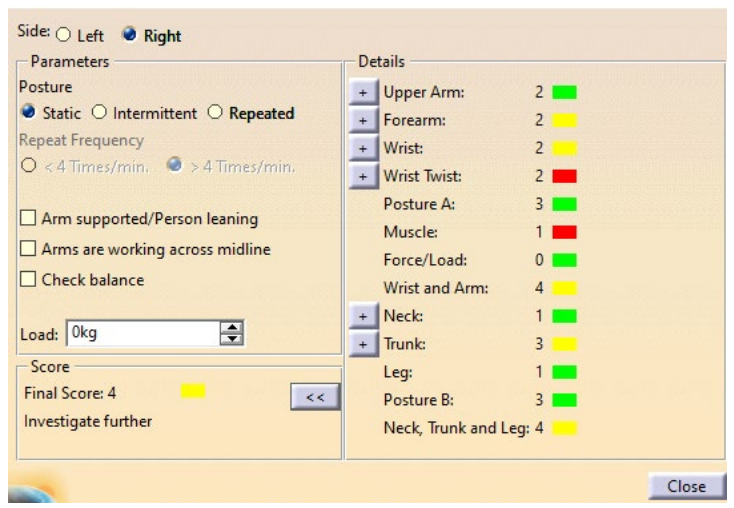

(b)

Şekil 10. (a) Alt bölüme ulaşılması, (b) RULA analiz sonucu (a) Reaching the lower section., (b) RULA analysis result

Modelin toplantı ve dinlenme bölümlerindeki oturma pozisyonunun RULA analiz sonuçları ise sırasıyla Şekil 11 ve 12 'de verilmiştir. Her iki oturma pozisyonunda final puanı 2 ve yeşil renk ile gösterilmiş ve herhangi bir değişiklik ihtiyacı olmadığı belirlenmiştir. 


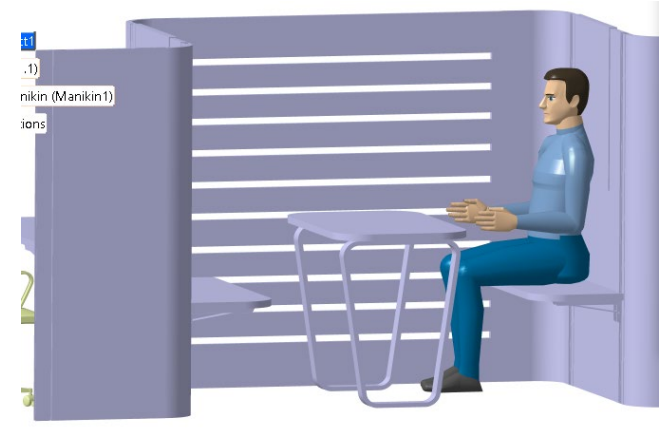

(a)

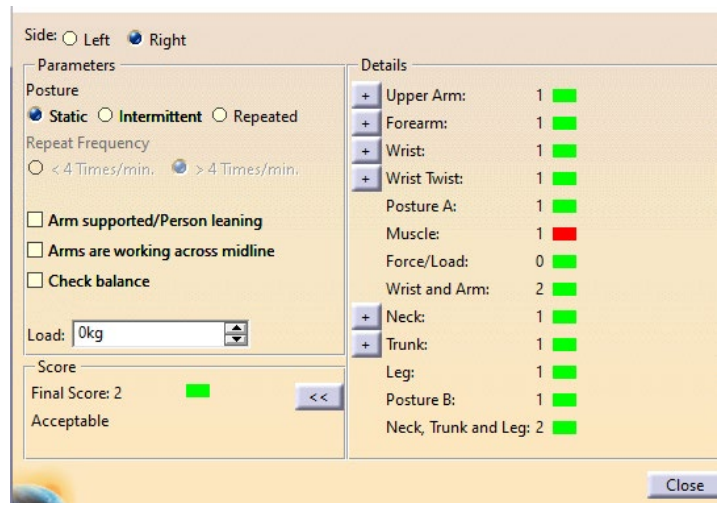

(b)

Şekil 11. (a) Toplantı bölümünde oturma pozisyonu, (b) RULA analiz sonucu (a) Sitting position in the meeting section, (b) RULA analysis result

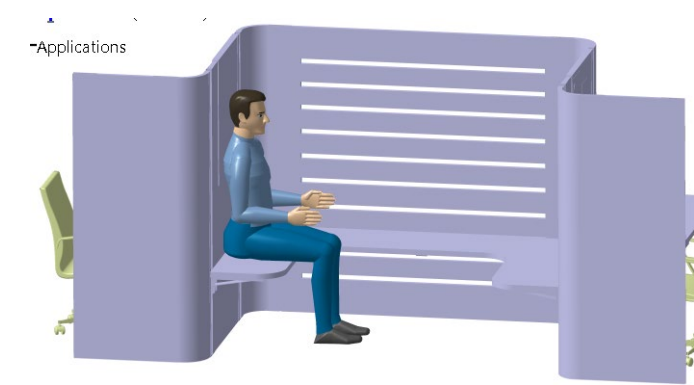

(a)

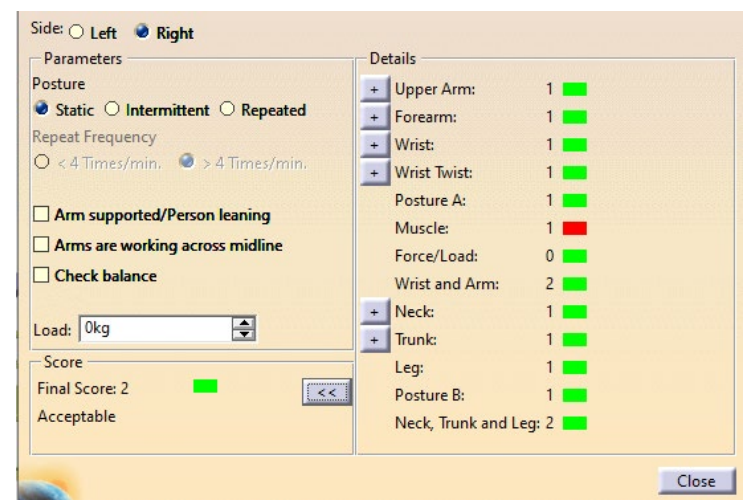

(b)
Şekil 12. (a) Dinlenme bölümünde oturma pozisyonu, (b) RULA analiz sonucu (a) Sitting position in the resting section, (b) RULA analysis result

Analiz işleminin tamamlanmasının ardından tasarlanan operasyonel ofis mobilyası tasarımının üst kısımdaki alt depolama biriminin kullanımında ortalama boy ölçüsüne sahip bir erkeğin duruş pozisyonunun ergonomik açıdan risk yaratacağ 1 tespit edilmiştir.

\section{RULA ANALİ SONUÇLARINA GÖRE YENIDEN TASARIM (REDESIGN BY RULA ANALYSIS RESULTS)}

CATIA V5 R21 programında gerçekleştirilen analiz sonuçlarına göre ofis mobilyası tasarımındaki depolama birimlerinin kullanımında ergonomik açıdan bireyler üzerinde risk yaratacağı tespit edilmiştir. Bu sebeple tasarım üzerinde bir takım değişiklikler gerçekleştirilmiştir. Var olan iki adet üst depolama birimi sayısı teke düşürülerek kalkar kapak kullanımı yerine raylı kapak tercih edilmiştir. Aynı zamanda dolap derinliği de azaltılarak farklı boy ölçülerine sahip bireylerin dolaba ulaşma durumu kolaylaştırılmıştır. Tasarımın alt kısmında bulunan çöp bölümü kulbu da kaldırılarak dolap kapağı ile entegre bir tutma yeri tasarlanmıştır. Böylece uzun boylu bireylerin alt bölüme ulaşmak için eğilme açısı azalmış olacaktır. Yeniden tasarımı gerçekleştirilen ofis mobilyası sisteminin çalışma birimi Şekil 13 'de verilmiştir.

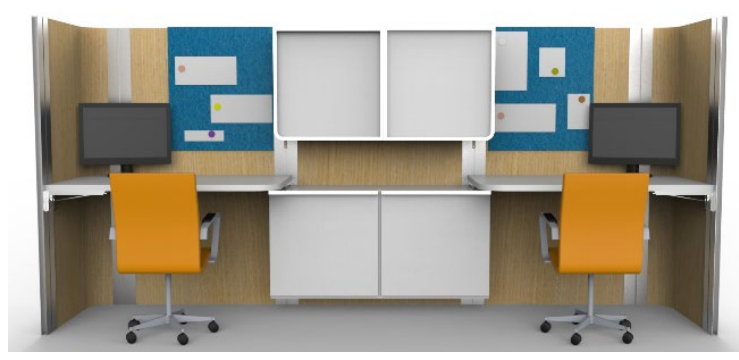

Şekil 13. Yeniden tasarımı gerçekleştirilen çalışma birimi (Redesigned working unit)

Yeniden tasarlanan model üzerine dijital insan modeli yerleştirilerek RULA analiz işlemi tekrarlanmıştır. Üst depolama birimi ve alt kısımdaki çöp bölümünün kulanım durumunun RULA analiz sonuçları sırası ile Şekil 14 ve 15 'te verilmiştir. 


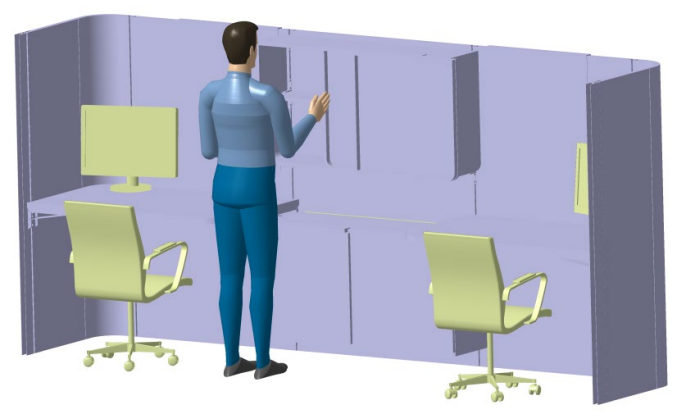

(a)

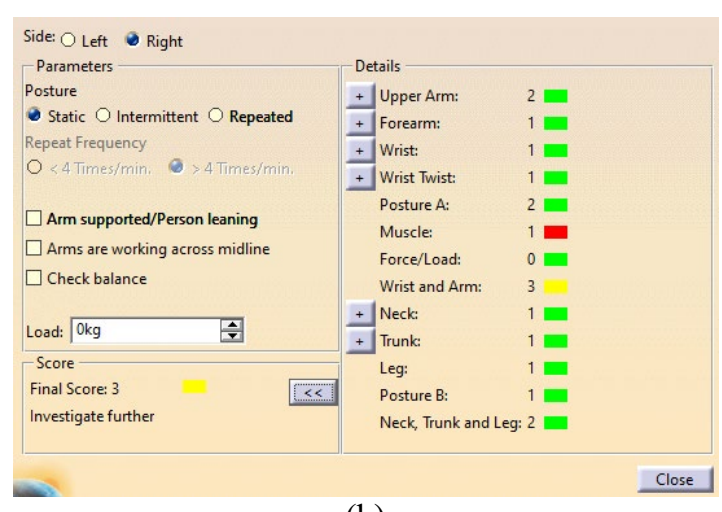

(b)

Şekil 14. (a) Yeniden tasarım sonrası üst kapağın aç1lması, (b) RULA analiz sonucu (a) Opening the top cover after redesign, (b) RULA analysis result

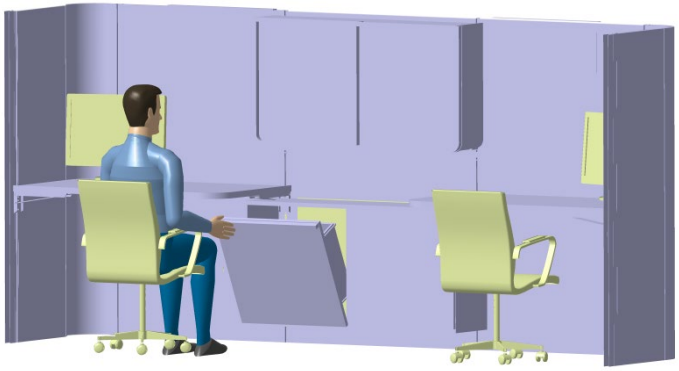

(a)

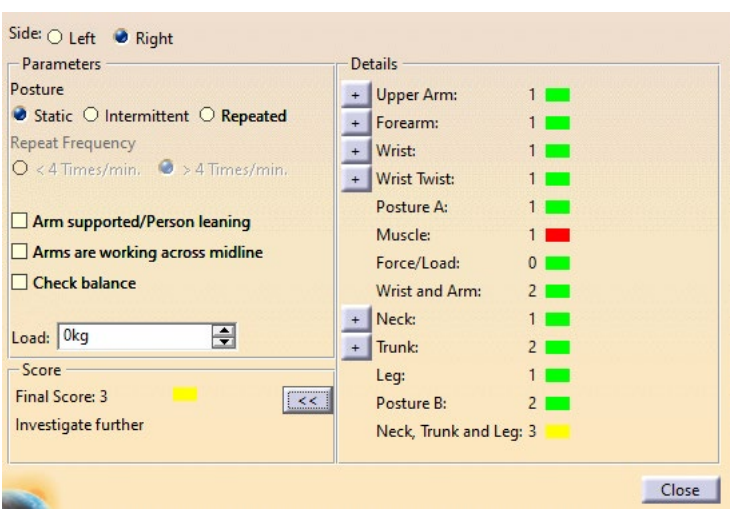

(b)
Şekil 15. (a) Yeniden tasarım sonrası alt bölüme ulaşılması, (b) RULA analiz sonucu (a) Reaching the lower section after redesign, (b) RULA analysis result

Ofis mobilyasının yeniden düzenlenen bölümlerinin RULA analiz sonuçlarına göre her iki final puanının da 3 ve sarı renk ile temsil edildiği görülmüştür. $\mathrm{Bu}$ durum, tasarım üzerinde yapılan değişikliklerin ergonomik anlamda olumlu sonuçlandığını göstermektedir.

\section{SONUÇ VE DEĞERLENDİRMELER (CONCLUSION AND EVALUATIONS)}

$\mathrm{Bu}$ çalışma kapsamında, değişen ofis tasarımlarına uygun olarak yarı açık yapıda düzenlenen operasyonel ofis mobilyası sistemi ergonomik açıdan değerlendirilmiştir. Analiz sürecinde CATIA programının RULA aracı kullanılarak çalışanların farklı duruş pozisyonları incelenmiştir. Çalışmada dijital insan modellerden yararlanılarak çalışma duruşları gerçeğe yakın bir şekilde modellenmiştir.

Elde edilen analiz sonuçlarına göre tasarım üzerinde ergonomik açıdan risk teşkil eden birimler tespit edilmiştir. Üst bölümdeki depolama birimlerini kullanma durumunda, ortalama vücut ölçülerine sahip bir çalışanın bile uzun vadede kas ve iskelet sisteminde problem oluşabileceği görülmüştür. Aynı şekilde alt bölümdeki birimlere oturma pozisyonunda ulaşılması durumunda da ergonomik açıdan risk meydana gelebileceği tespit edilmiştir. Elde edilen RULA analiz sonuçlarına göre yeniden tasarlanan ofis mobilyası sistemi tekrar analiz edilerek ilk elde edilen sonuçlarla kıyaslanmış ve düzenlemelerin olumlu sonuçlandı̆̆ belirlenmiştir.

\section{KAYNAKLAR)}

[1] Kaya, Ö., \& Özok, A. F. "Tasarımda antropometrinin önemi," Mühendislik Bilimleri ve Tasarım Dergisi, vol. 5, özel sayı, 2017. Doi: $10.21923 /$ jesd.45182.

[2] Phesant, S. Antropometrics, The British Library Document Supply Cantre, Boston. USA, 1990.

[3] Akın, G. "Yaşam kalitesinin artırılmasında antropometrinin önemi," Ankara Üniversitesi Dil ve Tarih-Coğrafya Fakültesi Dergisi, vol. 39, no. (1-2), pp. 87-101, 1999. 
[4] Ulijoszek, S. J. Mascie-Taylar, C. G. N. Antropometry, The Individual and The Population, Cambridge University Pres Great. Britain, 1994.

[5] Eldem, C., Top, N., Şahin, H. "Dijital İnsan Modelleri Kullanarak Otomobil Sürücüsü Duruş Pozisyonlarının Ergonomik Değerlendirilmesi Üzerine Bir Çalışma," Gazi Mühendislik Bilimleri Dergisi, vol. 5, no.1, pp. 22-31, 2019.

[6] Pheasant, S., Haslegrave, C. M. Bodyspace: Anthropometry, Ergonomics and the Design of Work, Third Edition, Boca Raton, 2018.

[7] Eldem, C., A., Şahin, İ., Demir, M., T., Top, N., Şahin, T. "Araç Bakım Kanallarının Dijital İnsan Modelleri İle Ergonomik Analizi ve Yeniden Tasarımı," Mühendislik Bilimleri ve Tasarım Dergisi, vol. 7, no. 2, pp. 386-392, 2019.

[8] Yararel, B. "Ofis Tasarımında Ergonomik ve Antropometrik Etkenler," Mimarlık ve Yaşam, vol. 4, no. 1, pp. 141-153, 2019.

[9] Top, N., Şahin, İ. “A Study On Modular Operational Working System Design In The Office Furniture Sector," The XXIXth International Conference Research for Furniture Industry, Ankara, Turkey, 2019.

[10]Harris, C.M., Handbook of Noise and Acoustical Measurement, Mc-Graw Hill, Bölüm 41, 1991.

[11] Gökçe, H., Gökçe, H. “Catia V5 ile Bilgisayar Destekli Optimizasyon Süreci”, Makine Teknolojileri Elektronik Dergisi, 10(1), 49-57, 2013.

[12] Şahin, İ., Eldem, C., Kalyon, S. A., Gökçe, H. "Digital Human Modelling and Ergonomic Analysis: Automatic Arm Barrier as an Example," International Congress on New Trends in Sicence, Engineering and Technology (ICONTRENDS'17), Barcelona, Spain, pp. 176187, 2017.

[13] Sencer, M., Eldem, C., Top, N., \& Şahin, İ. "RULA Yöntemi Kullanarak Şehir İçi Otobüslerdeki Havalandırma Pencerelerinin Ergonomik Analizi," International Symposium
On Automotive Science And Technology (ISASTECH), Ankara, Türkiye, 2019.

[14]Deste, M., \& Sever, S. "İmalat İşletmelerinde Ergonomik Risk Değerlendirme Yöntemleri Üzerine Bibliyometrik Bir Analiz," Ekev Akademi Dergisi, ICOAEF Özel Sayısı, pp. 209-224, 2019.

[15] T.R. Waters, V.P. Anderson, A. Garg and L.J. Fine, "Revised NIOSH equation for the Design and Evaluation of Manual Lifting Tasks," Ergonomics, vol. 36, no. 7, pp 749-776, 1993.

[16] L.H. Shy, "Ergonomic Intervention to Reduce the Risk of Musculoskeletal Disorders (MSDs) for Manual Materials Handling Tasks," Project Report, UTeM Malaysia, 2008.

[17] S. Rud. An Ergonomic Analysis of the Current Lifting Techniques in Height Restricted Cargo Bins at Company XYZ, Thesis, University of Wisconsin-Stout, 2011.

[18] Y.T. Medina, S.Vina. "Evaluation and Redesign of Manual Material Handling in a Vaccine Production Centre's Warehouse," A Journal of Prevention, Assessment and Rehabilitation, pp. 2487-2491, 2012.

[19] Akay, D., Kurt, M., \& Dağdeviren, M. "Çalışma Duruşlarının Ergonomik Analizi," Gazi Üniversitesi Mühendislik-Mimarlı Fakültesi Dergisi, vol. 18, no. 3, pp. 73-84, 2003.

[20] Jadhav, G. S., Sawant, S. M., Suresh M. Shinde, G., \& Jamadar, V. "Ergonomic Evaluation Tools RULA and REBA Analysis: Case study.," National Conference on Industrial Engineering and Technology Management, NITIE, Mumbai, 2014.

[21] Omar, A. R., Saad, N. H., \& Halim, I. "Ergonomic assessment using RULA analysis software to investigate musculoskeletal disorders (msds) experienced by material handler in metal stamping industries," Hand, 11378 (12962), 10738.

[22] Vaclav, S., Peterka, J., Pokorny, P. “Objective method for assembly," In Annals of DAAAM for 2007 \& Proceedings., Viedeň, ISSN 17269679, 2007. 
[23] Qutubuddin, S. M., Hebbal, S. S., \& Kumar, A. C. S. "Ergonomic Risk Assessment using Postural Analysis Tools in a Bus Body Building Unit," Industrial Engineering Letters, vol. 3, no. 8 , pp. $10-20$, 2013.

\section{Neslihan TOP}

1992 yılında Aydın'da doğdu. İlk, orta ve lise eğitimini Aydın'da tamamladı. 2014 yılında Gazi Üniversitesi Endüstri Ürünleri Tasarımı bölümünden mezun oldu. 2019 yllında Gazi Üniversitesi Endüstriyel Tasarım Mühendisliği bölümünde yüksek lisans eğitimini tamamladı ve bu bölümde araştırma görevlisi olarak çalışmaya devam etmektedir. 